\title{
Pengembangan Aplikasi Pendeteksi Potensi Bencana Gunung Berapi Menggunakan Pengklasifikasi Bayesian
}

\author{
Dewi Yanti Liliana \\ Prodi Teknik Informatika \\ Jurusan Teknik Informatika dan Komputer, Politeknik Negeri Jakarta \\ Jalan Prof. G.E. Siwabessy, Kampus UI, Depok, Jawa Barat \\ dewiyanti.liliana@tik.pnj.ac.id
}

Diterima: 15 Maret 2015. Disetujui: 23 April 2015. Dipublikasikan: Mei 2015

\begin{abstract}
Abstrak - Letak geografis Indonesia berada di pertemuan dua lempeng yaitu Asia dan Australia, menyebabkan banyak terdapat gunung berapi. Selain itu pegunungan di Indonesia didominasi oleh gunung yang aktif dan berpotensi meletus sewaktu-waktu. Kondisi tersebut mengharuskan warga negara Indonesia, khususnya yang tinggal di sekitar pegunungan berapi aktif tanggap akan bencana letusan gunung berapi. Berkembangnya sains dan teknologi informasi dapat memberi kontribusi dalam rangka mitigasi bencana geologi yang diakibatkan aktivitas vulkanik dalam bentuk aplikasi pendeteksi potensi bencana gunung berapi. Penelitian ini menghasilkan suatu aplikasi pendeteksi status gunung berapi. Data latih yang digunakan diambil dari situs Pusat Vulkanologi dan Mitigasi Bencana Gunung Berapi yang diklasifikasikan dalam tiga status yaitu normal, siaga, dan waspada. Pengklasifikasi Bayesian digunakan karena merupakan metode berbasis probabilitas yang sederhana namun handal. Berdasarkan hasil pengujian jumlah data latih terbesar mencapai tingkat akurasi $90 \%$. Dengan demikian dapat dikatakan bahwa aplikasi pendeteksi potensi bencana gunung berapi memiliki performa yang baik dalam mengklasifikasi status gunung berapi.
\end{abstract}

Kata Kunci: klasifikasi, bencana gunung berapi, pengklasifikasi bayesian, pembelajaran tersupervisi.

\section{PENDAHULUAN}

Posisi geografis Indonesia terletak di pertemuan dua lempeng Asia dan Australia, hal ini menyebabkan Indonesia sering mengalami gempa tektonik dan banyak muncul gunung berapi [1]. Indonesia memiliki lebih dari 400 gunung berapi dan 130 di antaranya termasuk gunung berapi aktif [2]. Sebagian dari gunung berapi terletak di dasar laut dan tidak terlihat dari permukaan laut. Indonesia merupakan tempat pertemuan dua rangkaian gunung berapi aktif (ring of fire). Terdapat puluhan patahan aktif di wilayah Indonesia. Menurut Kepala Pusat
Vulkanologi dan Bencana Geologi, Kementerian Energi dan Sumber Daya Mineral, dari 127 gunung api aktif di Indonesia hanya 69 yang terpantau dan itupun masih jauh dari keadaan ideal, baik dari segi peralatan maupun dari segi Sumber Daya Manusia [1].

Berdasarkan kondisi nyata yang ada di Indonesia maka disusunlah sebuah penelitian untuk mengimplementasikan aplikasi pendeteksi potensi bencana gunung berapi guna mengantisipasi dampak serta kerugian akibat bencana letusan gunung berapi. Status gunung berapi diklasifikasikan menjadi tiga kategori yaitu normal, siaga, dan waspada. Pengklasifikasi yang digunakan adalah Bayesian atau disebut Nä̈ve Bayes Classifier (NBC), sebuah metode pembelajaran mesin sederhana yang handal untuk mengenali pola. NBC bekerja dengan mencari probabilitas posterior dari suatu pola, kemudian mengklasifikasikan pola tersebut ke dalam kelas yang memiliki nilai posterior terbesar [3].

NBC merupakan metode pembelajaran tersupervisi, oleh karena itu diperlukan data latih sebagai data pembelajaran yang diambil dari situs resmi Pusat Vulkanologi dan Mitigasi Bencana Gunung Berapi (proxy.vsi.esdm.go.id/index.php). Data-set tersebut akan digunakan sebagai vektor fitur untuk mengklasifikasikan status gunung berapi.

\section{PERSAMAAN MATEMATIKA}

\section{A. Teorema Bayes}

Teorema Bayes merupakan pendekatan statistika dan probabilistik yang mendasari bidang pengenalan pola [4]. Jika $\mathrm{X}$ melambangkan himpunan fitur atau data dan $\mathrm{Y}$ melambangkan variabel kelas, apabila variabel kelas Y memiliki hubungan non-deterministik dengan fitur X maka X dan $\mathrm{Y}$ dapat dinyatakan sebagai variabel acak yang memiliki hubungan peluang bersyarat $\mathrm{P}(\mathrm{Y} \mid \mathrm{X})$. 
Peluang bersyarat $\mathrm{P}(\mathrm{Y} \mid \mathrm{X})$ juga dikenal dengan posterior probability. Bentuk umum persamaan Bayes adalah:

$$
P(H \mid \mathbf{X})=\frac{P(\mathbf{X} \mid H) P(H)}{P(\mathbf{X})}
$$

dimana:

$X \quad$ : data atau fitur yang ingin diduga kelasnya

$H \quad$ : hipotesis bahwa $X$ merupakan anggota kelas $H$

$P(X)$ : probabilitas $\mathrm{X}$

$P(H) \quad$ : probabilitas awal dari kelas $\mathrm{H}$ (prior probability)

$P(X \mid H)$ : probabilitas $X$ bersyarat kelas $\mathrm{H}$

$P(H \mid X)$ : probabilitas kelas $H$ dengan kondisi data $X$ (posterior probability)

$P(X \mid H)$ : conditional probability yang disebut dengan likelihood atau kecenderungan kejadian $X$ dengan syarat/kondisi kelas $H$.

Nilai prior probability dan likelihood dapat diperoleh dari eksperimen terhadap data latih [5]. Data X (dapat berupa vektor fitur) diklasifikasikan sebagai anggota kelas $\mathrm{C}$ jika posterior probability $\mathrm{P}(\mathrm{Ci} \mid \mathrm{X})$ adalah yang terbesar dibandingkan dengan posterior probability $\mathrm{P}(\mathrm{Ck} \mid \mathrm{X})$ dari seluruh kelas $\mathrm{k}$.

Untuk data latih yang bersifat kontinyu dapat digunakan persamaan 2 untuk mencari nilai likelihood (disebut juga formula distribusi Gauss) [1].

$$
P\left(X_{i}=x_{i} \mid Y=y_{j}\right)=\frac{1}{\sqrt{2 \pi \sigma_{i j}^{2}}} \exp ^{-\frac{\left(x_{i}-\mu_{i j}\right)^{2}}{2 \sigma_{i j}^{2}}}
$$

dimana $P$ melambangkan probabilitas, $\mathrm{X}_{\mathrm{i}}$ adalah

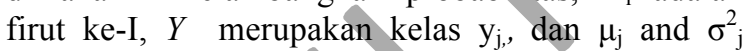
adalah rata-rata dan varian dari kelas $j$.

\section{B. Pengklasifikasi Bayesian (NBC)}

NBC adalah pengklasifikasi sederhana berbasis probabilitas yang menerapkan teorema Bayes. Keuntungan dari penggunaan NBC adalah hanya diperlukan relatif sedikit data latih untuk mengestimasi parameter yang diperlukan pada proses klasifikasi [6]. NBC mengestimasi probabilitas dari suatu kelas bersyarat dengan asumsi bahwa atribut data (fitur) adalah bebas bersyarat (conditionally independent) terhadap variabel kelas [7]. Conditional independent diekspresikan dalam persamaan 3, yaitu:

$$
P(X \mid Y=y)=\prod_{i=1}^{d} P\left(X_{i} \mid Y=y\right)
$$

dimana $X=\left\{X_{1}, X_{2, \ldots,} X_{d}\right\}$ adalah banyaknya fitur $(d$ buah fitur). Untuk mengklasifikasikan data tes, NBC mengkalkulasi probabilitas posterior dari setiap kategori kelas $Y$ lalu memutuskan kelas dengan nilai probabilitas posterior terbesar sebagai kategori kelas suatu data uji. Perhitungan probabilitas posterior $P(Y \mid X)$ suatu data latih yang memiliki beberapa fitur $X_{i}$ menggunakan formula 4

$$
P(Y \mid X)=\frac{P(Y) \prod_{i=1}^{d} P\left(X_{i} \mid Y\right)}{P(X)}
$$

\section{METODOLOGI PENELITIAN}

Metodologi penelitian meliputi beberapa tahapan yang digambarkan dalam diagram alir pada Gambar 1.

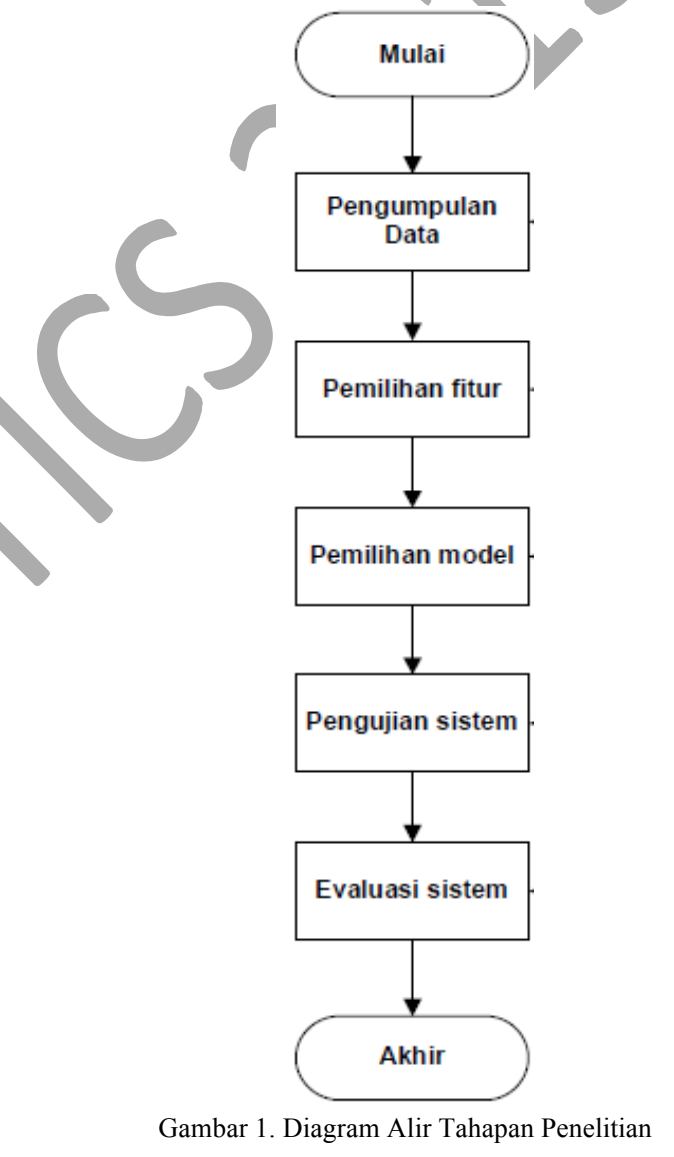

Proses penelitian diawali dengan pengumpulan data latih yang disebut dengan data set status gunung berapi. Selanjutnya ditentukan fiturfitur yang invarian, yaitu fitur yang merepresentasikan karakteristik status gunung berapi. Tahap berikutnya yaitu pemilihan model, bagaimana memodelkan fitur-fitur gunung berapi untuk mencari parameter probabilitas posterior dengan metode NBC berdasarkan data set yang ada. Selanjutnya dilakukan pengujian performansi aplikasi yang dibangun. Terakhir dilakukan evaluasi 
aplikasi untuk mengukur akurasi aplikasi yang telah dihasilkan.

\section{A. Pengumpulan Data}

Pada tahap pengumpulan data dikumpulkan data latih dari gunung berapi yang ada di Indonesia. Data-set ini berasal dari Pusat Vulkanologi dan Mitigasi Bencana Gunung Berapi, Kementerian Energi dan Sumber Daya Mineral. Data didapatkan pada situs resmi pusat tersebut, yaitu proxy.vsi.esdm.go.id/index.php [8]. Aktifitas suatu gunung berapi dipantau setiap hari oleh pusat tersebut sehingga reliabilitas data yang didapatkan bisa dipertanggung jawabkan.

\section{B. Pemilihan Fitur}

Berdasarkan pengamatan terhadap data yang dikumpulkan oleh Pusat Vulkanologi dan Mitigasi Bencana Gunung Berapi didapatkan beberapa data latih yang memiliki beberapa fitur dan kelas kategori[2]. Fitur tersebut adalah Vulkanik Dangkal, Tektonik Jauh, dan Vulkanik Dalam. Sedangkan Kategori kelas yaitu siaga, waspada, dan normal. Tabel 1 dan Tabel 2 menunjukkan data-set yang digunakan.

\begin{tabular}{|c|c|c|c|c|}
\hline \multirow[t]{2}{*}{ Data } & \multicolumn{3}{|c|}{ Fitur } & \multirow[t]{2}{*}{ Keputusan } \\
\hline & $\begin{array}{l}\text { Vulkanik } \\
\text { Dangkal }\end{array}$ & $\begin{array}{c}\text { Tektonik } \\
\text { Jauh }\end{array}$ & $\begin{array}{c}\text { Vulkanik } \\
\text { Dalam }\end{array}$ & \\
\hline Data 1 & 16 & 113 & 15 & Siaga \\
\hline Data 2 & 2 & 67 & 2 & Waspada \\
\hline Data 3 & 44 & 4 & 128 & Siaga \\
\hline Data 4 & 79 & 1 & 24 & Waspada \\
\hline Data 5 & 77 & 7 & 6 & Waspada \\
\hline Data 6 & 1 & 60 & 1 & Waspada \\
\hline Data 7 & 10 & 30 & 45 & Siaga \\
\hline Data 8 & 44 & 3 & 62 & Normal \\
\hline Data 9 & 143 & 2 & 3 & Siaga \\
\hline Data 10 & 49 & 2 & 1 & Waspada \\
\hline Data 11 & 1 & 49 & 8 & Normal \\
\hline Data 12 & 9 & 29 & 43 & Normal \\
\hline Data 13 & 2 & 130 & 24 & Siaga \\
\hline Data 14 & 1 & 40 & 3 & Normal \\
\hline Data 15 & 13 & 114 & 39 & Siaga \\
\hline Data 16 & 3 & 47 & 39 & Normal \\
\hline Data 17 & 51 & 3 & 7 & Waspada \\
\hline Data 18 & 45 & 13 & 93 & Siaga \\
\hline Data 19 & 6 & 51 & 77 & Siaga \\
\hline Data 20 & 13 & 59 & 27 & Normal \\
\hline Data 21 & 78 & 4 & 57 & Waspada \\
\hline Data 22 & 4 & 76 & 37 & Normal \\
\hline Data 23 & 4 & 76 & 85 & Siaga \\
\hline Data 24 & 65 & 70 & 6 & Siaga \\
\hline Data 25 & 70 & 45 & 34 & Waspada \\
\hline Data 26 & 17 & 90 & 6 & Siaga \\
\hline Data 27 & 8 & 22 & 92 & Siaga \\
\hline Data 28 & 92 & 26 & 10 & Waspada \\
\hline Data 29 & 5 & 78 & 10 & Normal \\
\hline Data 30 & 12 & 17 & 58 & Siaga \\
\hline
\end{tabular}




\begin{tabular}{|l|l|l|l|l|l|}
\hline Data 7 & waspada & Waspada & waspada & waspada & siaga \\
\hline Data 8 & waspada & Waspada & waspada & waspada & waspada \\
\hline Data 9 & waspada & Waspada & waspada & waspada & waspada \\
\hline Data 10 & siaga & Siaga & siaga & siaga & siaga \\
\hline Data 11 & normal & Normal & normal & normal & normal \\
\hline Data 12 & siaga & Waspada & siaga & siaga & siaga \\
\hline Data 13 & normal & Normal & normal & normal & normal \\
\hline Data 14 & normal & Waspada & waspada & siaga & siaga \\
\hline Data 15 & normal & Waspada & waspada & waspada & waspada \\
\hline Data 16 & siaga & waspada & waspada & siaga & waspada \\
\hline Data 17 & waspada & waspada & waspada & waspada & waspada \\
\hline Data 18 & waspada & waspada & waspada & waspada & waspada \\
\hline Data 19 & normal & waspada & normal & waspada & waspada \\
\hline Data 20 & siaga & siaga & normal & normal & normal \\
\hline
\end{tabular}

Pada percobaan pertama yang menggunakan 15 data-set, dari 20 percobaan, 13 data uji sesuai dengan fakta yang ada, dan 7 lainnya masih salah. Dengan demikian tingkat akurasinya adalah $65 \%$. Percobaan ke-2 menggunakan 20 data-set. Hasilnya adalah 15 data dari 20 data yang diuji memberikan hasil yang sama dengan fakta sebenarnya, dengan 5 hasil lainnya tidak sesuai dengan fakta. Tingkat akurasinya sebesar $75 \%$. Percobaan ke-3 menggunakan jumlah data-set sebanyak 25 data. Hasil yang sesuai fakta sebanyak 16 data, dan 4 yang lainnya masih tidak sesuai dengan fakta. Tingkat akurasi sebesar 80\%. Percobaan ke-4 menggunakan data-set sebanyak 30 data. Hasilnya 18 data dari 20 data tersebut sesuai dengan fakta, sementara 2 lainnya masih salah klasifikasi. Dengan demikian tingkat akurasi mencapai $90 \%$.

Grafik pada Gambar 2 menyimpulkan hubungan antara jumlah data latih dengan tingkat akurasi. Semakin besar jumlah data latih akan meningkatkan akurasi pengenalan oleh aplikasi.

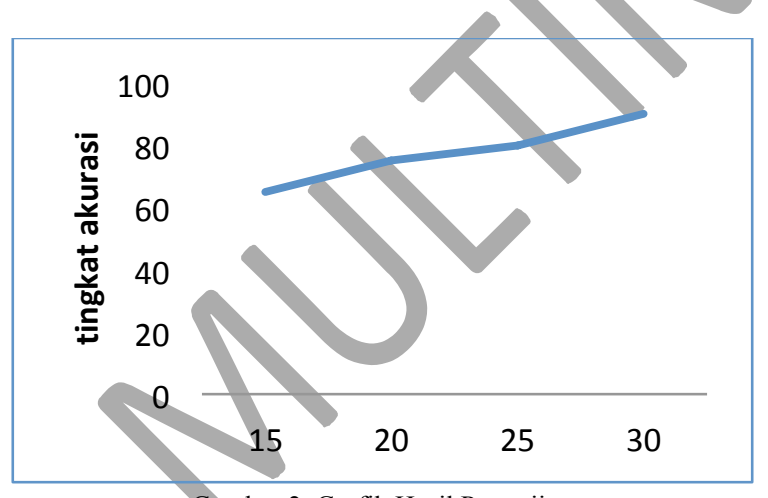

Gambar 2. Grafik Hasil Pengujian

\section{KESIMPULAN}

Penelitian ini telah menerapkan Nä̈ve Bayesian Classifier sebagai Early Warning System status gunung berapi berdasarkan fitur nilai Tektonik Jauh, Vulkanik Dangkal, dan Vulkanik Dalam suatu gunung berapi, kemudian dapat dikenali status suatu gunung berapi apakah termasuk salah satu kelas yaitu siaga, normal, atau waspada. Tingkat akurasi tertinggi mencapai $90 \%$ dengan jumlah data latih sebanyak 30 data. Penambahan data latih memberi dampak yang signifikan terhadap akurasi aplikasi. Selanjutnya dapat dikembangkan real time system untuk memantau status gunung berapi.

\section{REFERENSI}

[1] Lessy, M. Zonasi Gempa Bumi di Indonesia, http://www.academia.edu/4517794/Zonasi_Gempa_bumi_di _Indonesia diakses, 2 November 2013.

[2] Butaru, R. Posisi Indonesia dan Kerentanan terhadap Bencana. http://bulletin.penataanruang.net/upload/data artikel/posisi\%20indonesia.pdf, diakses 1 November 2013.

[3] Duda, O. Richard, Hart, P. E, and Stork, D. G, "Pattern Classification (2nd ed)", John Wiley \& Sons, 2000

[4] Theodoridis, Sergios, Koutroumbras, Konstantin, Pattern Recognition ( $4^{\text {th }}$ ed), Prentice Hall, 2005

[5] Zeng T; Zheng L; Yang Li; Chen X; Long T. Offline Performance Prediction of PDAF With Bayesian Detection for Tracking in Clutter. IEEE Transactions on Signal Processing. Year: 2013, Volume: 61, Issue: 3 Pages: 770 781

[6] Graham, Paul, 2003. Better Bayesian filtering. Downloaded at http://vvww.paulgraham.com/better.html Salib, Michael. 2002. "Meat Slicer: Spam Classification with Naive Bayes and Smart Heuristics ".

[7] Lingyan D; Yuqiao Wen; Jiang Ma. Dual tree complex wavelet transform and Bayesian estimation based denoising of poission-corrupted X-ray images. 2013 Fourth International Conference on Intelligent Control and Information Processing (ICICIP). Year: 2013 Pages: 598 603

[8] proxy.vsi.esdm.go.id/index.php, diakses tanggal 5 november 2013 